\title{
The Relationship between Personality Traits and Behavioral Problems among Adolescents in Malaysia
}

\author{
Tin Zhi Ling, Jessemine Khoo Ai Pheng, Wong Wan Sin, Tan Soon-Aun*
}

Department of Psychology and Counselling, Faculty of Arts and Social Science, Universiti Tunku Abdul Rahman, Jalan Universiti, Bandar Barat, 31900

Kampar, Perak

*Corresponding author: tansa@utar.edu.my

\begin{abstract}
The increased rates of behavioral problems among adolescents are alarming in Malaysia. Previous studies indicated that individuals' personality traits may contribute to the engagement of behavioral problems among adolescents. However, there are still limited published researches in Malaysia context. Thus, this study aimed to investigate the effect of personality traits on internalizing and externalizing behavioral problems among adolescents in Malaysia. There were 480 school-going adolescents aged between 13 to 17 years old, recruited by using multistage cluster sampling method from Selangor, Perak and Kedah states of Malaysia. Two instruments used in this study were Big Five Inventory (BFI), and Strength and Difficulties Questionnaire (SDQ). The results of the study showed that the higher the level of openness, conscientiousness, extraversion and agreeableness and the lower the level of neuroticism were linked to the low tendency in the engagement of internalizing and externalizing behavioral problems among adolescents in Malaysia. Regression analyses indicated that personality traits of neuroticism appeared to be the strongest predictor for both adolescents' internalizing and externalizing behavioral problems. Findings of the study stressed the importance of understanding adolescents' personality traits when studying on adolescents' internalizing and externalizing behavioral problems. Hence, the provision of social skills and coping strategies among adolescents are necessary to promote better human development.
\end{abstract}

Keywords: Internalizing, externalizing, personality traits, adolescents

(C) 2017 Penerbit UTM Press. All rights reserved

\subsection{INTRODUCTION}

The period between childhood and adulthood, ages from 10 to 19, is a period of lifespan development of adolescence (WHO, 2015). It is a transition period that involved the changes in biological, socio-emotional, and cognitive (Santrock, 2012). Several experiences that adolescents might have include the problems in searching their identity, social skills to interact with others, forming relationships, and the desire for freedom and independent from their parents (WHO, 2015; Santrock, 2012). According to Erik Erikson's Theory, adolescents search for identity and strive for independence to make their own decision (Erikson, 1968). Adolescents have higher tendency to feel lost about their future direction and this might lead them to be unable to cope with the social expectation, thus creating internalizing and externalizing behavioral problems (Cherry, 2005).

Adolescents' problematic behaviors have raised a serious concern in Malaysia as the statistics of children and adolescent who committed crime such as drug offence, stealing and house breaking has doubled to nearly 10,000 cases in 2008 as compared to 2003 (Ministry of Women, Family and Community Development \& UNICEF Malaysia, 2013). In addition, juveniles' crime had also increased from 3700 cases in 2012 to 7816 cases in 2013 (The star online, 2014). In determining adolescents' internalizing and externalizing behavioral problems, it is important to study their personality traits (Karaman, 2013). It is attributed that personality traits may determine the chances of adolescents to engage in problem behaviors by depending on their ability to cope with life adversities (Hambrick \& McCord, 2010; Feil \& Haskings, 2008). Numerous statistical evidences have found adolescents with low extraversion and high neuroticism are highly related to internalizing behavioral problems such as anxiety (Mezquita, Ibáñez, Villa, Fañanás, Moya-Higueras, \& Ortet, 2015; Slobodskaya \& Akhmetova, 2010), sleeping disorders (Patankar, 2013; Lau, 2013), and suicide behaviors (Zilber, 2009). In contrast, adolescents with low level of openness, conscientiousness, and agreeableness have higher tendency to involve in externalizing behavioral problems such as aggression (Jones, Miller \& Lynam2011), drug use, theft (Chang, 2013; Torrente \& Vazsonyi, 2012), risky behaviors (Torres \& Pritchard, 2006) and so forth. Mixed results showed that adolescents with high level of extraversion will also tend to have higher tendency to involve in externalizing behavioral problems (Slobodskaya \& Akhmetova, 2010; Markey, Markey, Ericksen, \& Tinsley, 2006) or have better coping skills that decrease the chances to involve in externalizing behavioral problems (Mirnics et al., 2013).

Previous studies have proven that there is relationship between personality traits of extraversion, neuroticism, conscientiousness, and agreeableness with adolescents' internalizing and externalizing behavioral problems (Mezquita et al., 2015; Patankar, 2013; Lau, 2013; Little, Hawkins, Sanson, O'Connor, Toumbourou, Smart, \& Vassallo, 2013; Mirnics et al., 2013; Herzhoff \& Tackett, 2012; Settles, Fischer, Cyders, Combs, Gunn, \& Smith, 2012; Slobodskaya \& Akhmetova, 2010; Torres \& Pritchard, 2006). Additionally, it is believed that various personality traits contributed differently in presenting different types of behavioral problems. Hence, this study aimed to investigate the relationships between personality traits with both internalizing and externalizing behavioral problems among adolescents in Malaysia. 
As displays in Figure 1, personality traits (openness, conscientiousness, extraversion, agreeableness, and neuroticism) were served as independent variable in this study. These independent variables were expected to link with dependent variable in this study, which were behavioral problems (internalizing and externalizing). The link between personality traits and behavioral problems were supported by previous study (Mezquita et al., 2015; Patankar, 2013; Chang, 2013; Lau, 2013; Torrente \& Vazsonyi, 2012; Jones et al., 2011; Slobodskaya \& Akhmetova, 2010; Fayombo, 2010; Zilber, 2009; Markey et al., 2006) In a nutshell, this study aimed to investigate the relationship between personality traits and behavioral problems among adolescents in Malaysia.

Independent Variable

\begin{tabular}{|c|c|}
\hline Personality & Behavioral Problem \\
\hline -Openness & -Internalizing \\
\hline $\begin{array}{l}\text {-Conscientiousness } \\
\text {-Extraversion } \\
\text {-Agreeableness } \\
\text {-Neuroticism }\end{array}$ & -Externalizing \\
\hline
\end{tabular}

Figure 1 Conceptual framework of the study on "the relationship between personality traits and behavioral problems among adolescents in Malaysia"

\subsection{LITERATURE REVIEW}

\section{Personality Traits and Internalizing Behavioral Problems}

According to Santrock (2012), personality referred to the enduring personal characteristics of individuals. Internalizing behavioral problems are characterized by behaviors that result from negativity that is focused inward (Slobodskaya \& Akhmetova, 2010). Based on the literatures in related area, previous studies have utilized Big Five factors of personality which comprised of openness to experience, conscientiousness, extraversion, agreeableness, and neuroticism to test their link with adolescents' internalizing behavioral problems (Mezquita et al., 2015; Patankar, 2013; Lau, 2013; Herzhoff \& Tackett, 2012; Fayombo, 2010; Slobodskaya \& Akhmetova, 2010; Zilber 2009; Markey et al., 2006). However, existing literatures found that openness, conscientiousness, and agreeableness were not related with adolescents' internalizing behavioral problems (Herzhoff \& Tackett, 2012; Slobodskaya \& Akhmetova, 2010; Markey et al., 2006).

Studies conducted by Slobodskaya and Akhmetova (2010) and Mezquita et al. (2015) revealed that extraversion was negatively correlated with children's and adolescents' internalizing behavioral problems. Low extraversion was associated with more negative emotions which increased the tendency of children and adolescents to develop internalizing behavioral problems (Slobodskaya \& Akhmetova, 2010) such as social anxiety (Mezquita et al., 2015). Neuroticism on the other hand was found to be highly correlated with adolescents' internalizing behavioral problems (Mezquita et al., 2015; Patankar, 2013; Lau, 2013; Fayombo, 2010; Zilber 2009). According to these researchers, individuals who scored high on neuroticism were more prone to worry, anxiety, and upset which consequently increased their chances to suffer from health related issues such as sleeping and eating disorders (Lau, 2013; Patankar, 2013; Fayombo, 2010) as well as higher vulnerability for suicidal behaviors (Zilber, 2009).

Overall, openness, conscientiousness, and agreeableness were found not to be correlated with adolescents' internalizing problems (Herzhoff \& Tackett, 2012; Slobodskaya \& Akhmetova, 2010; Markey et al., 2006). In contrast, low extraversion (Mezquita et al., 2015; Slobodskaya \& Akhmetova, 2010) and high neuroticism (Mezquita et al., 2015; Patankar, 2013; Lau, 2013; Fayombo, 2010; Zilber, 2009) were found to be correlated with internalizing behavioral problems.

\section{Personality Traits and Externalizing Behavioral Problems}

Externalizing behavioral problems are characterized by behaviors that are directed towards the external environment, either to other people or things (Slobodskaya \& Akhmetova, 2010). Past studies revealed that openness to experience has mixed effects on adolescents' externalizing behavioral problems (Herzhoff \& Tackett, 2012; Jones et al., 2011; Slobodskaya \& Akhmetova, 2010; Ardalan, Iravani \& Sobhi-Gharamaleki, 2010). Some researchers have found no relation between openness to experience and adolescents' externalizing behavioral problems, however they claimed that openness to experience might act as a protective factor against behavioral problems (Herzhoff \& Tackett, 2012; Slobodskaya \& Akhmetova, 2010). In contrast, studies showed that there was a significant negative correlation between openness to experience and behavioral problems (Jones et al., 2011; Ardalan et al., 2010). These researchers have found that low level of openness was associated with adolescents' delinquency behaviors (Ardalan et al., 2010) and high aggression (Jones et al., 2011).

Existing literatures also highlighted that adolescents who have low conscientiousness have higher tendency to develop externalizing behavioral problems (Dubey, Arora, Gupta, \& Kumar, 2010; Chang, 2013; Torrente \& Vazsonyi, 2012; Ardalan et al., 2010). Evidences supported that adolescents who scored low on conscientiousness tend to have higher chances to involve in externalizing behavioral problems such as substance abuse (Dubey et al., 2010), vandalism, drug use, theft (Chang, 2013; Torrente \& Vazsonyi, 2012), and delinquency (Ardalan et al., 2010).

Neuroticism was found to be weakly correlated with adolescents' externalizing behavioral problems (Mezquita et al., 2015; Slobodskaya \& Akhmetova, 2010). However, some researchers found evidences of the relationship between this personality domain and adolescents' externalizing behavioral problems (Settles et al., 2012; Ardalan et al., 2010). Adolescents who scored higher level of neuroticism had higher tendency to act rashly (Settles et al., 2012) and involved in juvenile delinquency (Ardalan et al., 2010). 
In relation to extraversion, previous studies (Mirnics et al., 2013; Slobodskaya \& Akhmetova, 2010; Markey et al., 2006) have shown inconsistent results on this link with externalizing behavioral problems. Some of the research findings indicated that high level of extraversion tend to increase the tendency for adolescents to be involved in externalizing behavioral problems (Slobodskaya \& Akhmetova, 2010; Markey et al., 2006) whereas other study revealed that extraversion served as protective factors against behavioral problems (Mirnics et al., 2013). Slobodskaya and Akhmetova (2010) found that high level of extraversion in children and adolescents caused them to be more impulsive which eventually led them to have difficulties in regulating their behaviors. In addition, Markey et al. (2006) revealed that high level of extraversion was also associated with adolescents' risky behaviors. On the other hand, Mirnics et al. (2013) found that extraversion was negatively related to externalizing behavioral problems among adolescents. Mirnics et al. (2013) denoted that adolescents who had higher level of extraversion also tend to have higher coping abilities which consequently led to better behavioral adjustments in their life and thus decreased their chances of being involved in behavioral problems.

Most of the past studies have found that agreeableness were negatively correlated with adolescents' externalizing behavioral problems (Little et al., 2013; Leeuw, Scholte, Sargent, Vermulst, \& Engels, 2010; Turchik, Garske, Probst, \& Irvin, 2010; Raynor \& Levine, 2009; Torres \& Pritchard, 2006) Their results indicated that adolescents who scored low on agreeableness have higher tendencies to be engaged in externalizing behavioral problems such as smoking (Leeuw et al., 2010), alcohol-related harms and consumption (Little et al., 2013; Raynor \& Levine, 2009), sexual risk taking behaviors (Turchik et al., 2010), and risky behaviors (Torres \& Pritchard, 2006).

Overall, low conscientiousness and agreeableness was found to be the main contributors of adolescents' externalizing behavioral problems (Chang, 2013; Little et al., 2013; Torrente \& Vasoznyi, 2012; Dubey et al., 2010; Ardalan et al., 2010; Leeuw et al., 2010; Turchik et al., 2010; Raynor \& Levine, 2009; Torres \& Pritchard, 2006). Openness and extraversion showed mixed results on adolescents' externalizing behavioral problems (Mirnics et al., 2013; Herzhoff \& Tackett, 2012; Jones et al., 2011; Slobodskaya \& Akhmetova, 2010; Ardalan et al., 2010; Markey et al., 2006). Some researchers found a negative relationship between neuroticism and externalizing behavioral problems among the adolescents (Settles et al., 2012; Ardalan et al., 2010) although neuroticism was found to be only weakly correlated with adolescents' externalizing behavioral problems (Mezquita et al., 2015; Slobodskaya \& Akhmetova, 2010). Although past studies have shown inconsistent associations between the Big Five personality traits and adolescents' behavioral problems, this study has expected that the personality traits of extroversion, agreeableness, conscientiousness, neuroticism and openness were significant predictors of both internalizing as well as externalizing behavioral problems among Malaysian adolescents.

\subsection{METHODOLOGY}

\section{Participants}

This study utilized multistage cluster sampling to select the respondents of the study. A total of 465 secondary school adolescents aged ranged from 13 to 17 years old $(M=15.05, S D=1.02)$ were selected from six secondary schools located at Kedah, Perak and Selangor. From the total of 465 samples, $51 \%$ of them were female. A total of $53.8 \%$ of respondents were Malay, followed by Chinese (30.5\%), Indian (11.8\%) and other ethnic groups (3.9\%). Prior to data collection, approval from Ministry of Education Malaysia (MOE), Jabatan Pendidikan Negeri (JPN), Pejabat Pendidikan Daerah (PPD) and schools were obtained. Parental consent was distributed and collected before adolescents participate in this study as part of ethical consideration.

\section{Measures}

Survey questionnaires were used as a tool to collect the data of the study. Back to back translation procedure was utilized to translate the measures from English to Malay language as Malay language is the national language used in the education setting of secondary national schools in Malaysia. Two instruments used in this study included the Big Five Inventory (BFI) and Strength and Difficulties Questionnaire (SDQ).

\section{Big Five Inventory (BFI)}

The Big Five Inventory with 44-item by John and Srivastava (1999) had in five point Likert scales ranging from 1 (Disagree Strongly) to 5 (Agree Strongly). It measures an individual on the Big Five Factors of personality dimensions such as openness to experience, conscientiousness, extraversion, agreeableness, and neuroticism. An individual is high on that particular dimension when higher scores are obtained. Conversely, lower score on any one of the dimension indicates that the person is low on that particular dimension. In this study, the reliability of the BFI subscales ranged between .60 to .78. As highlighted by Gurven, von Rueden, Massenkoff, Kaplan, and Lero Vie (2013), developing countries such as Malaysia and South American, the use of BFI in measuring personality traits often showed lower reliability which averaging 0.64 .

\section{Strength and Difficulties Questionnaire (SDQ)}

Strength and Difficulties Questionnaire (SDQ) developed by Goodman (1997) was used to measure internalizing and externalizing behavioral problems among adolescents. There were a total of 25 items measuring five subscales which included emotional symptoms scale, conduct problems scale, hyperactive/inattention scale, peer relationship problems scale and prosocial behavior scale in SDQ. Each of the items is scored based on three point Likert scales: not true (0), somewhat true (1) and certainly true (2). Emotional symptoms scale and peer relationship problems scale were being used to measure internalizing behavioral problems while conduct problems scale and hyperactive/inattention scale were being used to measure externalizing behavioral problems (Goodman, Lamping, \& Ploubidis, 2010). Higher scores in the total score of emotional symptom scale and peer relationship problems scale indicated higher levels of internalizing behavioral problems, conversely higher scores in the total score of conduct problems scale and hyperactive/inattention scale implied higher 
levels of externalizing behavioral problems. The reliability for total score of internalizing behavioral problems is .678 while for total score of externalizing behavioral problems is .657 respectively.

\title{
Data Analysis
}

SPSS version 21 was used to analyze the data of the study. Three levels of analysis were conducted to test the hypothesis of the study. First, descriptive statistics were operated to examine the pattern of the variables understudy and also construct the background of the study sample. Next, Pearson correlation analysis was presented to determine the relationship between various personality traits with both adolescents' internalizing and externalizing behavioral problems. Lastly, multiple regression analyses were conducted to identify the unique contribution of personality traits on internalizing and externalizing behavioral problems among adolescents in Malaysia.

\subsection{ANALYSIS AND DISCUSSION}

\author{
Personality Traits And Internalizing Behavioral Problem
}

Descriptive statistics which included the mean and standard deviation were used to summarize the distribution of data collected of the study (refer Table 1). As described in Table 1, Pearson correlation analysis was used to measure the relationship between independent variables (personality traits) and dependent variables (internalizing behavioral problems and externalizing behavioral problems). The results of the study revealed a negative significant relationship between extraversion, agreeableness, conscientiousness and internalizing behavioral problems. In the opposite direction, neuroticism was positively correlated with adolescents' internalizing behavioral problems. This indicated that adolescents who scored high in extraversion, agreeableness, conscientiousness and low in neuroticism have lower tendency to involve in internalizing behavioral problems. However, no significant relationship was found between openness personality trait and internalizing behavioral problems.

The results of this study that found no significant relationship between openness to experience and internalizing behavioral problems is consistent with previous studies (Herzhoff \& Tackett, 2012; Slobodskaya \& Akhmetova, 2010). The reason of this result is unexplored (Slobodskaya \& Akhmetova, 2010). However, Herzhoff and Tackett (2012) explained that openness to experience might act as a protective factor to internalizing behavioral problems. This is because individuals who scored high in openness to experience are more ready to face any changes or challenges in life and hence, they have better behavioral adjustment.

Besides that, extraversion showed a negative relationship with internalizing behavioral problems. This result is further supported by past studies (Mezquita et al., 2015; Slobodskaya \& Akhmetova, 2010;) which implied that adolescents with low extraversion will increase their proneness in developing internalizing behavioral problems. This is because adolescents with low extraversion are reserved, spend less time on social activities and know only few friends. Hence, when they experience negative feelings, they tend to keep to themselves and thus increase the chance of involving in internalizing behavioral problems such as social anxiety (Mezquita et al., 2015). Thus, adolescents with high extraversion are less prone to internalizing behavioral problems as compared to those with low extraversion.

On the other hand, the results of this study indicated that conscientiousness personality trait is negative correlated with internalizing behavioral problems. Jensen-Campbell and Malcolm (2007) noted that adolescents who have history of being victimized under peer aggression tend to have low conscientiousness. This is because adolescents with low conscientiousness tend to have emotional instability such as easier to have feelings of anxious and fearful. Hence, it further leads them to be prone to internalizing behavioral problems and under victimization of peer aggression. In addition, they also have difficulties in regulating their emotions and keep focusing on those negative emotions and stimuli that posing higher risk to involve in internalizing behavioral problems (Kushner, Tackett \& Bagby, 2012).

Moreover, a negative correlation between agreeableness and internalizing behavioral problems was found in this study. Previous findings further supported the result of this study (McGhee, Ehrler, Buckhalt, \& Phillips, 2012; Torrente \& Vazsonyi, 2012). Adolescents with low agreeableness are portrayed to be more suspicious and have problems in emotional regulation may leading them to have interpersonal problems and further lead them to involve in internalizing behavioral problems. Thus, this showed that individuals with high agreeableness are less prone to internalizing behavioral problems.

In contrast, there is a positive relationship found between neuroticism and internalizing behavioral problems. This result is consistent with previous studies (Patankar, 2013; Fayombo, 2010; Zilber, 2009). Individuals who are high in neuroticism are more likely to face difficulties in regulating their negative emotions. These difficulties make them to feel unease in their daily life and thus will cause them to have higher chances to develop internalizing behavioral problems such as depression and anxiety.

\section{Personality Traits And Externalizing Behavioral Problem}

In relation to externalizing behavioral problems, results highlighted a positive relationship with neuroticism. Furthermore, negative correlations were found between agreeableness, conscientiousness and openness with externalizing behavioral problems. However, extraversion was not significant related to externalizing behavioral problems. This means that adolescents with externalizing behavioral problems were normally high in neuroticism, low in agreeableness, conscientiousness and openness personality traits.

In this study, the results indicated that extraversion is not significant correlated with externalizing behavioral problems. This is further supported by previous studies (Torres \& Pritchard, 2006; Cravens-Brown, 2002). This insignificant results may due to individuals with high extraversion are described to be more impulsive but yet they will still empathize with other.

On the other hand, there is a negatively significant correlation between agreeableness and externalizing behavioral problems which was supported by past studies (Little et al, 2013; Torres \& Pritchard, 2006; Leeuw et al., 2010; Turchik et al., 2010). Individuals with low agreeableness are prone to externalizing behavioral problems because they are lacking of cooperativeness and overly suspicious (McGhee et al., 2012; Torrente \& Vazsonyi, 2012). Furthermore, individuals who are low in agreeableness tend to disobey the laws and norms which leading them to have higher risk to involve in externalizing behavioral problems (Leeuw et al., 2010; Raynor \& Levine, 2009). 
The study also found that conscientiousness is significantly negative correlated with externalizing behavioral problems. This is further supported by previous researches (Chang, 2013; Torrente \& Vazsonyi, 2012; Dubey et al., 2010), where Individuals with high conscientiousness are less prone to externalizing behavioral problems due to their self-regulation ability (Torrente \& Vazsonyi, 2012). This is because individual with low conscientiousness is described as a person who lack of self-control and lower opinion of self-abilities, thus placing them with higher possibility to engage in externalizing behavioral problems.

Besides, there is also a negative relationship between openness to experience and externalizing behavioral problems as supported by previous findings (Ardalan et al., 2010; Jones et al., 2011). Ardalan et al. (2010) declared that adolescents who involved in delinquency tend to have lower openness to experience. This is because individuals who scored low in openness to experience are being characterized as easier to face distressing emotions and are prone to externalizing behavioral problems. Adolescents who are high in openness to experience act as a protective factor against externalizing behavioral problems (Jones et al., 2011). This is because they tend to experience more positive affect and feelings. Thus, adolescents with high openness will decrease the risk of developing externalizing behavioral problems.

The research findings showed neuroticism is positively correlated with externalizing behavioral problems. This result is further supported by previous studies (Lau, 2013; Shakerian, Nazari, Masoomi, \& Ebrahimi, 2013; McGhee et al., 2012; Settles et al., 2012). Individuals with high level of neuroticism are prone to externalizing behavioral problems due to their impulsivity, anxiety and other negative emotions such as depression and angry (Lau, 2013; McGhee et al., 2012). Besides, these individual are prone to feel tense, frustrated, guilty and moody. They also tend to act harshly when facing emotional distress these encourage risk predictor of externalizing behavioral problems (Settles et al., 2012).

Table 1 Descriptive statistics and correlations among variables $(\mathrm{N}=453)$

\begin{tabular}{|c|c|c|c|c|c|c|c|c|}
\hline Variables & Mean & $S D$ & 1 & 2 & 3 & 4 & 5 & 6 \\
\hline 1. Extraversion & 26.53 & 4.34 & 1 & & & & & \\
\hline 2. Agreeableness & 32.55 & 4.21 & $.31 * * *$ & 1 & & & & \\
\hline 3. Conscientiousness & 30.10 & 5.30 & $.29 * * *$ & $.53 * * *$ & 1 & & & \\
\hline 4. Neuroticism & 21.97 & 5.02 & $-.26 * * *$ & $-.38 * * *$ & $-.46 * * *$ & 1 & & \\
\hline 5. Openness & 32.96 & 4.57 & $.34 * * *$ & $.34 * * *$ & $.36 * * *$ & $-.17 * * *$ & 1 & \\
\hline 6. Internalizing & 6.20 & 3.35 & $-.25 * * *$ & $-.18 * * *$ & $-.24 * * *$ & $.51 * * *$ & -.06 & 1 \\
\hline 7. Externalizing & 6.28 & 3.19 & -.09 & $-.36 * * *$ & $-.48 * * *$ & $.48 * * *$ & $-.17 * * *$ & 60 *** \\
\hline
\end{tabular}

\section{Personality Traits As Predictor Of Internalizing Behavioral Problem}

Table 2 showed the findings on personality trait as predictors of internalizing and externalizing behavior among adolescents in Malaysia. The first model was generated to investigate the predictors for internalizing problems among adolescents in Malaysia. In this model, the $\mathrm{R}^{2}$ $=.275$ revealed that the combination of personality traits: extraversion, agreeableness, conscientiousness and neuroticism explained $27.5 \%$ of the variance in adolescents' internalizing problems. The results of regression analysis revealed that two variables were significantly contributed to adolescents' internalizing behavioral problems. Personality trait of neuroticism $($ Beta $=.49, \mathrm{p}<.001)$ appeared to be the strongest predictor of adolescents' internalizing behavioral problems, followed by personality trait of extraversion $($ Beta $=-.13, p<.01)$. The results of this study showed that neuroticism serve as a very strong predictor of adolescents' internalizing behavioral problems which is consistent with previous findings (Patankar, 2013; Zilber, 2009; Fayombo, 2010; Lau, 2013). Adolescence during this developmental stage faced crises to gain personal freedom while searching for their own identity (Adamski \& Joshi, 2014). These crises may cause the onset of neurotic symptoms such as being harsh and lead to emotional imbalance as well as being stubborn and disobedient. Adolescents with high neuroticism are at higher risk to engage in internalizing behavioral problems if these symptoms are being ignored. Previous researchers implied that adolescents with high neuroticism are prone to negative affect such as fussiness, anxiousness, agitation (Patankar, 2013) and depressive (Zilber, 2009). Furthermore, failure to regulate these negative emotions may cause adolescents to internalize behavioral problems causing dangerous behaviors or disorders. Fayombo (2010) and Lau (2013) further explained that adolescents high in neuroticism have higher chances to experience negative internalizing symptoms such as upset and tension. Adolescents who fail to cope with such stressful situations might lead them to develop internalizing behavioral problems. Thus, neuroticism personality trait plays an important role in the development of internalizing behavioral problems among adolescents.

Besides neuroticism, extraversion also served as another significant predictor of internalizing behavioral problems among adolescents. Previous findings indicated that extraversion is a strong predictor of internalizing behavioral problems (Mezquita et al., 2015; Slobodskaya \& Akhmetova, 2010). Lack of social activity and social skills among adolescents with low extraversion will cause them to experience more negative and unpleasant emotions which lead to the development of internalizing behavioral problems. Mezquita et al. (2015) stated that individuals who are high in extraversion have fewer chances to involve in internalizing behavioral problems. This is because these individual with high extraversion trait are outgoing, assertive, warmth and friendly. Thus, extraversion can serve as one of the protective factors for adolescents who suffer from internalizing behavioral problems.

\section{Personality Traits Predictor Of Externalizing Behavioral Problem}

In predicting on adolescents' externalizing behavioral problems, the $\mathrm{R}^{2}$ in this model is .320 which implied that the combination of personality traits: agreeableness, conscientiousness, neuroticism and openness explained 32.0\% of the variance in adolescents' externalizing problems. The results of regression analysis indicated that both conscientiousness $($ Beta $=-.29, p<.001)$ and neuroticism $($ Beta $=.32, \mathrm{p}<.001)$ significantly explained adolescents' externalizing behavioral problems. 
In this study, neuroticism personality trait acts as the strongest predictors for adolescents' externalizing behavioral problems. This is consistent with previous studies (Lau, 2013; Shakerian et al., 2013; McGhee et al., 2012) which stressed that neuroticism plays a main role in predicting adolescents' externalizing behavioral problems. Adolescents high in neuroticism are impulsive, anxious, depressive, hostility, upset and these cause them to have higher chances in developing externalizing behavioral problems when they fail to regulate their emotions and behaviors. Moreover, feelings of tension, irritation, disappointment and shame are widespread among adolescents with high neuroticism resulting in the development of externalizing behavioral problems. According to Fetterman, Robinson, Ode and Gordon (2010), individuals high in neuroticism also showed lack of self-control in their behaviors. Hence, these implied that neuroticism plays an important role in predicting engagement of adolescents in externalizing behavioral problems.

Furthermore, result of this study also highlighted conscientiousness as another important predictor in developing adolescents' externalizing behavioral problems. Previous study also stressed that individuals with low conscientiousness are prone to externalizing behavioral problems such as criminal behaviors (Chang, 2013; Torrente \& Vazsonyi, 2012) and substance abuse (Dubey et al., 2010). Adolescents with low conscientiousness show a lack of skills in regulating their behaviors and emotions, this causing them to have higher risk in getting involved in externalizing behavioral problems. In addition, lack of self-control among adolescents with low conscientiousness also caused them prone to externalizing behavioral problems (Dubey et al., 2010). This is because their failure to cope with daily life stressor resulted in their inability to control their behaviors. Therefore, conscientiousness personality trait served as one of the main predictors in explaining adolescents' externalizing behavioral problems.

Table 2 Predictors of internalizing and externalizing behavior among adolescents in Malaysia $(\mathrm{n}=453)$

\begin{tabular}{|c|c|c|c|c|c|c|c|}
\hline Criterion variable & Predictor variable & $\mathbf{F}$ & $\mathbf{R}^{2}$ & df & Beta & $\mathbf{t}$ & Sig. \\
\hline \multirow{4}{*}{ Internalizing } & Extraversion & $42.444 * * *$ & .275 & $(4,448)$ & $-.13 * *$ & -3.10 & .002 \\
\hline & Agreeableness & & & & .05 & 1.10 & .273 \\
\hline & Conscientiousness & & & & -.01 & -.09 & .927 \\
\hline & Neuroticism & & & & $.49 * * *$ & 10.61 & .000 \\
\hline \multirow[t]{4}{*}{ Externalizing } & Agreeableness & $52.699 * * *$ & .320 & $(4,448)$ & -.09 & -1.78 & .074 \\
\hline & Conscientiousness & & & & $-.29 * * *$ & -5.87 & .000 \\
\hline & Neuroticism & & & & $.32 * * *$ & 7.12 & .000 \\
\hline & Openness & & & & .02 & .36 & .723 \\
\hline
\end{tabular}

Note: $* * * p<.001 ; * * p<.01$

\subsection{PRACTICAL IMPLICATIONS}

As a conclusion, adolescents who were high on neuroticism and low on conscientiousness were more vulnerable to externalizing behavioral problems while adolescents who were high on neuroticism and low on extraversion have higher chances to suffer from internalizing behavioral problems. Hence, in order to decrease the tendency of adolescents from developing the internalizing and externalizing problems, several interventions should be promoted to decrease the level of neuroticism and increase the level of conscientiousness and extraversion. Adolescents who scored low on the extraversion and high on neuroticism were more likely to have low social coping skills having difficulties to adapt in their social life, such as how to interact with others or making friends. In order to decrease these internalizing problems tendency, schools teacher or counselor can help adolescents to increase their extraversion by encouraging them to join programs to foster their social skills, and also inculcate some coping skills and emotional regulations strategies to those who are high on neuroticism. This can help them to decrease their level of neuroticism and instill their social development.

Adolescents low on conscientiousness exhibit impulsive behavior and lack of self-monitoring. Hence, in order to help adolescents to increase their level of conscientiousness, parents and teachers are encouraged to enforce and practice strict rules. It is believed that through proper parental supervision and monitoring, adolescents' social contact is able to avoid the negative influence from their peers which in turn lower the tendency to develop externalizing behavioral problems.

Besides, this study also enrich the knowledge gap by providing the empirical evident on the contribution of personality traits on adolescents problem behavior. Furthermore, government, schools, parents, teachers as well as individual need to consider adolescents' personality factors in order to effectively dealing with their behavioral problem.

Generally, parents and teachers are important parties to promote and enhance adolescents' social skills and coping strategies in order to prevent them from develop internalizing and externalizing behavioral problem.

\subsection{LIMITATIONS AND FUTURE DIRECTIONS}

The findings of the study should be interpreted with limitations. First, this was a cross-sectional based research which focused only on data collected in a particular period. Future study are recommended to carry out longitudinal research which will provide better point of view on how a particular development experiences affect the internalizing and externalizing behavioral problems. Secondly, this study only focused on adolescents' personality dimension, there are other important variables that need to be considered in future studies such as childhood experiences, family and environmental issues which were believed to have also contributed to the development of adolescents' behavioral problems. Lastly, this study only focused on internalizing and externalizing behavioral problems as whole but not on specific internalizing and externalizing behavioral problems such as anxiety, relational aggression and aggressive behavior. Future studies should emphasize on more specific internalizing and externalizing behavioral problems. 


\section{References}

Adamski, K. M. N. \& Joshi, S. (2014). Personality, Musicality And Mental Health In South Asian Classical Musicians. International Journal of Advanced Research, 2(2), 343-348

Ardalan, D., Iravani, M., \& Sobhi-Gharamaleki, N. (2010). A Comparison Of The Personality Characteristics Of Delinquent And Non-Delinquent Juveniles of Tehran, Iran. International Journal of Criminology and Sociological Theory, 3(1), 372-384.

Chang, Y. O. (2013). Adolescent Personality, Confucian Values, Parenting Typologies And Adolescent Behavioral Outcomes: A Study in South Korea. (Unpublished doctoral dissertation). Syracuse University.

Cherry, K. A. (2005). Erikson's Stages Of Psychosocial Development. About Education. Retrieved on November 15, 2014 from http://psychology.about.com/od/psychosocialtheories/a/psychosocial.htm

Cravens-Brown, L. M. (2002). Eysenck and Antisocial Behavior: An Analysis of the Associations between Personality Styles and Problems with Conduct. (Unpublished doctoral dissertation). The Ohio State University.

Dubey, C., Arora, M., Gupta, S., \& Kumar, B. (2010). Five Factor Correlates: A Comparison Of Substance Abusers And Non-Substance Abusers. Journal of the Indian Academy of Applied Psychology, 36(1), 107-114

Erickson, E. (1968). Identity: Youth and crisis. New York: Norton.

Fayombo, G. (2010). The relationship Between Personality Traits And Psychological Resilience Among The Caribbean Adolescents. International Journal of Psychological Studies, 2(2), 105-116.

Feil, J. \& Hasking, P. (2008). The Relationship Between Personality, Coping Strategies And Alcohol Use. Addiction Research and Theory, $16(5), 526-537$.

Fetterman, A. K., Robinson, M.D., Ode, S., \& Gordon, K. H. (2010). Neuroticism as A Risk Factor For Behavioural Dysregulation: A mindfulness-mediation perspective. Journal of Social and Clinical Psychology, 29(3), 301-321.

Goodman, A., Lamping, D. L., Ploubidis, G. B. (2010). When to Use Broader Internalising And Externalising Subscales Instead Of The Hypothesised Five Subscales on the Strengths and Difficulties Questionnaire (SDQ): data from British parents, teachers and children. Journal of Abnormal Child Psychology, 38, 11791191.

Goodman, R. (1997). The Strengths and Difficulties Questionnaire: A Research Note. Journal of Child Psychology and Psychiatry, 38, 581-586.

Gurven, M., von Rueden, C., Massenkoff, M., Kaplan, H., \& Lero Vie, M. (2013). How Universal Is the Big Five? Testing the Five-Factor Model of Personality Variation among Forager-Farmers in the Bolivian Amazon. Journal of Personality and Social Psychology, 104(2), 354-370.

Hambrick, E. P. \& McCord, D. M. (2010). Proactive Coping And Its Relation To The Five Factor Model Of Personality. Individual Differences Research, 8(2), 67-77.

Herzhoff, K. \& Tackett, J. L. (2012). Establishing Construct Validity For Openness-To-Experience In Middle Childhood: Contributions From Personality And Temperament. Journal of Research in Personality, 46, 286-294.

Jensen-Campbell, L. A. \& Malcolm, K. T. (2007). The Importance of Conscientiousness in Adolescent Interpersonal Relationships. Personality and Social Psychology Bulletin. 33(3), 368-383.

John, O. P. \& Srivastava, S. (1999). The Big-Five Trait Taxonomy: History, Measurement, And Theoretical Perspectives. In L. Pervin and O.P. John (Ed.), Handbook of Personality: Theory And Research, 102-138. New York: The Guilford Press.

Jones, S., Miller, J. D., \& Lynam, D. R. (2011). Personality, Antisocial Behavior, And Aggression: A Meta-Analytic Review. Journal of Criminal Justice, 39, 329337.

Karaman, G. N. (2013). Predicting the Problem Behavior In Adolescents. Eurasian Journal of Educational Research, 52, $137-154$.

Kushner, S. C., Tackett, J. L. \& Bagby, R. M. (2012). The Structure of Internalizing Disorders in Middle Childhood and Evidence for Personality Correlates. Journal of Psychopathology Behavior Access, 34, 22-34.

Lau, S. K. (2013). Big Five Personality Traits, Pathological Personality Traits, And Psychological Dysregulation: Predicting Aggression And Antisocial Behaviors In Detained Adolescents. (Unpublished doctoral dissertation). University of New Orleans.

Leeuw, R. N. H., Scholte, R. H., Sargent, J. D., Vermulst, A. A., \& Engels, R. C. (2010). Do Interactions Between Personality And Social-Environmental Factors Explain Smoking Development In Adolescence? Journal of Family Psychology, 24(1), 68-77.

Little, K., Hawkins, M. T., Sanson, A., O'Connor, M., Toumbourou, J. W., Smart, D., \&Vassallo, S. (2013). Longitudinal Predictors Of Alcohol-Related Harms During The Transition To Adulthood. Australian Psychologist, 48(4), 270-280.

Markey, C. N., Markey, P. M., Ericksen, A. J., \& Tinsley, B. J. (2006). Children's Behavioral Patterns, The Five-Factor Model Of Personality, And Risk Behaviors. Personality and Individual Differences, 41, 1503-1513.

McGhee, L. R., Ehrler, J. D., Buckhalt, A. J., \& Phillips, C. (2012). The Relation Between Five-Factor Personality Traits And Risk-Taking Behavior In Preadolescents. Scientific Research, 3(8), 558-561.

Mezquita, L., Ibáñez, M. I., Villa, H., Fañanás, L., Moya-Higueras, J., \& Ortet, G. (2015). Five-Factor Model And Internalizing And Externalizing Syndromes: A 5year prospective study. Personality and Individual Differences, 79, 98-103.

Ministry of Women, Family and Community Development \& UNICEF Malaysia. (2013).The Malaysian Juvenile Justice System: A Study Of Mechanisms For Handling Children In Conflict With The Law. Retrieved October 22, http://www.unicef.org/malaysia/The_Msian_Juvenile_Justice_System_Nov_13_R2.pdf

Mirnics, Z., Heincz, O., Bagdy, G., Surányi, Z., Gonda, X., Benko, A., Molnar, E., Jakšić, N., Lazary, J., \& Juhasz, G. (2013) The Relationship Between The Big Five Personality Dimensions And Acute Psychopathology: Mediating And Moderating Effects Of Coping Strategies. Psychiatria Danubina, 25(4), 379-388.

Patankar, S. D. (2013). Neuroticism in Adolescent Boys And Girls. Indian Streams Research Journal, 3(2), 1-7.

Raynor, D. A. \& Levine, H. (2009). Associations Between The Five-Factor Model Of Personality And Health Behaviors Among College Students. Journal of American College Health, 58(1), 73-82.

Santrock, J. W. (2012). Adolescence (14th Ed.). New York: McGraw-Hill.

Settles, R. E., Fischer, S., Cyders, M. A., Combs, J. L., Gunn, R. L., \& Smith, G. T. (2012). Negative Urgency: A Personality Predictor Of Externalizing Behavior Characterized By Neuroticism, Low Conscientiousness, And Disagreeableness. Journal Of Abnormal Psychology, 121(1), 160-172.

Shakerian, A., Nazari, A. M., Masoomi, M., \& Ebrahimi, P. (2013). Investigating Personality Trait And Pre-Marital Affair With Opposite Sex Among University Students of Sanandaj City.Procedia - Social and Behavioral Sciences, 114(1), 339-345.

Slobodskaya, H. A. \& Akhmetova, O. A. (2010). Personality Development And Problem Behavior In Russian Children And Adolescents. International Journal of Behavioral Development, 34(5), 441-451.

The Star Online (2014). Juvenile Crime On The Rise. Retrieved from: http://www.thestar.com.my/Opinion/Letters/2014/04/14/Juvenile-crime-on-the-rise/

Torrente, G. \& Vazsonyi, A. T. (2012). Personality, Parenting And Deviance Among Spanish Adolescents. Anales de Psicología, $28(3), 654-664$.

Torres, A. A. \& Pritchard, M. (2006). Personality Characteristics as Predictors of Health Risk Behaviors. Rocky Mountain Psychological Association Annual Meeting.

Turchik, J. A., Garske, J. P., Probst, D. R., \& Irvin, C. R. (2010). Personality, Sexuality, And Substance Use As Predictors Of Sexual Risk Taking In College Students Journal of Sex Research, 47(5), 411-419.

WHO (2015). Maternal, Newborn, Child And Adolescent Health. Adolescent development. Retrieved from: http://www.who.int/maternal_child_adolescent/topics/adolescence/dev/en/

Zilber, I. (2009). The Role Of Neuroticism In Depressive And Anxious Symptoms Among Adolescents From Urban And Rural China. (Unpublished master dissertation).The State University of New Jersey. 